\title{
Gallstone ileus: A cause of intestinal obstruction
}

\section{Safra taşı ileusu: bir intestinal obstrüksiyon nedeni}

\author{
Hasan Besim, Mehmet İnan, Kadir Koray Baş*
}

Department of General Surgery (Prof. H. Besim, MD, Assist. Prof. K. K. Baş, MD), Near East University School of Medicine, Nicosia /TRNC, General Surgery Unit (M. İnan, MD), Magusa Medical Center Hospital, Famagusta /TRNC

\begin{abstract}
A case with gallstone ileus is presented in this article. The patient was hospitalized with findings of small intestine obstruction and a gallstone was excised from the jejunum. No intervention was performed in the area of cholecysto-duodenal fistula. After the operation, the patient recovered without any complication. This rare disease is discussed along with its surgical treatment options in view of the literature.
\end{abstract}

Keywords: Gallstone, ileus, intestinal fistula

\section{Özet}

$\mathrm{Bu}$ makalede safra taşı ileusu olan bir olgu sunulmuştur. Hasta ince barsak obstrüksiyon bulguları ile yatırılmış ve jejunumdan bir safra taşı eksize edilmiştir. Kolesisto-duodenal fistül bölgesine herhangi bir girişim yapılmamıştır. Operasyon sonrasında hasta komplikasyonsuz olarak iyileşmiştir. Yazıda bu nadir hastalık cerrahi tedavi seçenekleri ile literatür ışığında tartışılmıştır.

Anahtar sözcükler: Safra taşı, ileus, intestinal fistül

Geliş tarihi/Received: February 9, 2012; Kabul tarihi/Accepted: April 2, 2012

\section{*Corresponding author:}

Kadir Koray Baş, MD, Department of General Surgery, Near East University Hospital, Nicosia/Northern Cyprus, Mersin 10, Turkey. E-mail: drkoraybas@yahoo.com

\section{Introduction}

Gallstone ileus is a rare cause of small intestine obstruction. It constitutes 1-3\% of the causes of mechanical obstruction of the small intestine [1]. Despite the high prevalence of gallstones, this entity is very rarely observed to cause ileus and its clinical diagnosis is difficult [2]. Morbidity and mortality rates of the disease are high due to old age, accompanying diseases and delayed diagnosis [3]. If the gallstone is found in an intestinal area other than the stomach where it can be excised with endoscopic methods, the treatment is generally surgery after general stabilization of the patient with appropriate replacements. It is still a controversial issue whether to close the cholecysto-duodenal fistula after excision of the stone with enterotomy. While enterotomy and stone excision is preferred for elderly patients with high comorbidity rates, who are at high risk for long durations of anesthesia, closure of the fistula is also recommended in eligible patients.

A case, which was admitted with small intestine obstruction, diagnosed with gallstone ileus and treated surgically, is presented in this report.

\section{Case report}

A 80 year-old female patient presenting with abdominal pain, distension, nauseavomiting and impaired general condition was admitted to Magusa Medical Center Hospital. Her history showed that the patient had been having nausea and vomiting for 
approximately 4-5 days and she had to be hospitalized on the last day due to deterioration of these complaints. There was no special condition in her history except hypertension and a gallstone detected with ultrasonography in the past years. Abdominal distension, epigastric tenderness and hypoactive bowel sounds were detected in her examination. Her rectum was full in the rectal examination and no pathological finding was observed. The patient had no history of prior abdominal surgery or herniation of the anterior abdominal wall. Her vomit had consisted of her meals during the first days, but later it consisted of bile and contents of the small intestine. In her examinations, 2-3 air-liquid levels of the small intestine were detected in ambulatory direct abdominal radiography and dilated small intestine segments and contracted gall bladder were detected in abdominal ultrasonography (USG). No gallstones were observed in the gall bladder lumen or any other area. Blood tests revealed that white blood cell count increased from $11.800 / \mathrm{mm}^{3}$ to $13.600 / \mathrm{mm}^{3}$ and blood glucose level was $344 \mathrm{mg} / \mathrm{dL}$. Considering the gallstone history, her abdomen USG was re-evaluated but no additional finding was observed. With these findings, the patient was monitored for diagnosis of mechanical intestinal obstruction and newly detected diabetes mellitus. First, regulation of blood glucose and intravenous liquid-electrolyte replacement were initiated. Nasogastric decompression could not be performed as the patient did not agree and cooperate. The patient's blood glucose was regulated and she was given a liquid-electrolyte replacement treatment during monitoring; however, a decision for surgery was taken due to her impaired clinical presentation and increased distension. During the exploration, it was observed that proximal jejunal segments were dilated and cyanotic, and the cause of obstruction was a gallstone with a diameter of $3 \mathrm{~cm}$, which had passed through the cholecystoduodenal fistula and obstructed the distal jejunal segment (Figures 1 and 2). The intestinal segments proximal to the obstruction were dilated and cyanotic. The gallstone was excised with enterotomy and the proximal dilated small intestines were decompressed through this area. The enterotomy site was closed with two-fold 3/0 Vicryl ${ }^{\circledR}$ sutures. During the intraabdominal exploration, it was observed that the gall bladder was highly fibrotic and fistulized to the duodenum from the corpus section. No stones were palpated in the gall bladder and choledochus. The small intestines and colon were checked for a second stone. The surgery was finalized without planning any intervention to the gall bladder and fistula. The patient was discharged upon recovery on the 5th day following postoperative care. She is still leading a healthy life at home.

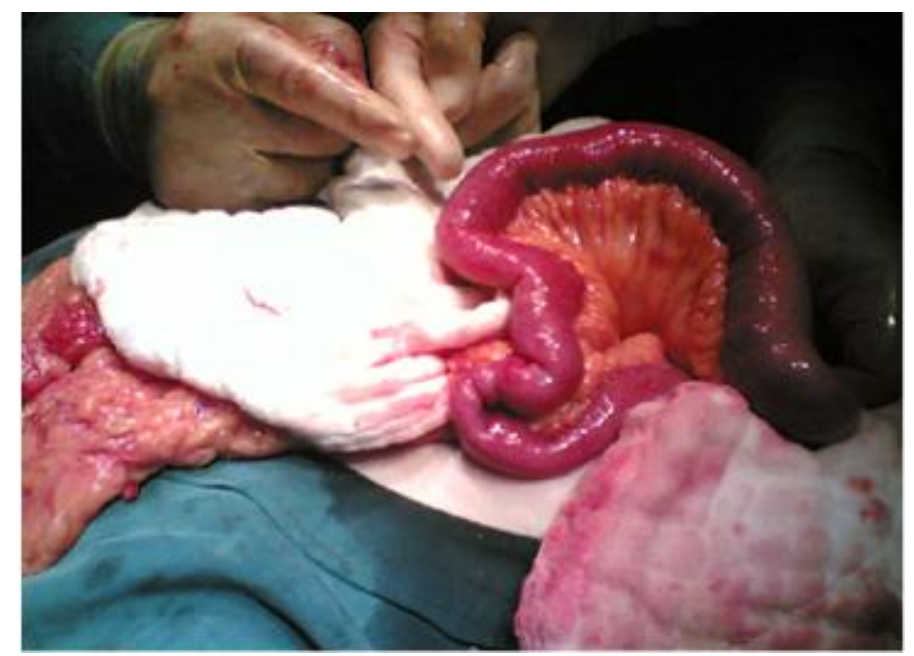

Figure 1. Proximal dilated and cyanotic jejunal segments and empty intestinal segments with normal colors distal to the gallstone. 


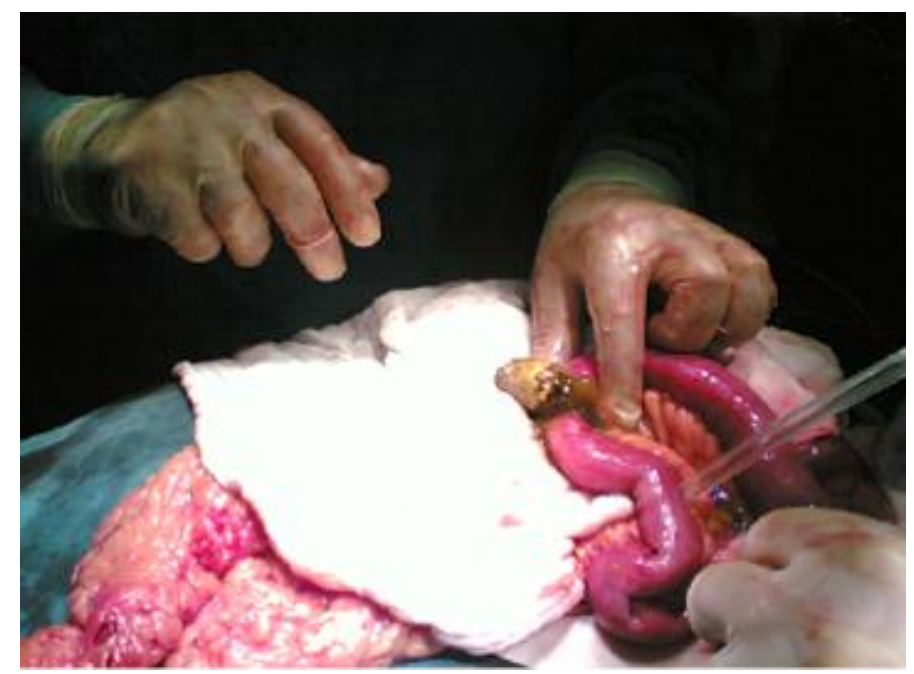

Figure 2. Excision of the gallstone with enterotomy and decompression of the small intestine.

\section{Discussion}

Gallstone ileus is a rare case, in which a stone that is normally found in the gall bladder or other areas of the biliary system usually passes through an internal fistula between the gall bladder and duodenum, leading to intestinal obstruction [4]. It was first described in 1654 by Bartholin as a disease of elderly people in need $[1,5]$. While obstruction is generally observed in terminal ileum, jejunum or duodenum can also be obstructed. Duodenal obstruction, with a clinical presentation of gastric outlet stenosis, is named "Bouveret Syndrome" after the person defining this presentation in 1896 [2, 4-6]. Gallstone ileus constitutes 1-3\% of all mechanical obstructions of the small intestine, while this ratio is $25 \%$ in the $>65$ year-old group $[1,7]$. Treatment of this disease results in a $12-18 \%$ high mortality, due to associated medical conditions (diabetes mellitus, hypertension, coronary artery disease, chronic obstructive pulmonary disease) and older age $[1,3]$. Another factor responsible for high morbidity and mortality is the delay in planning of appropriate treatment due to challenges in diagnosis [1]. Gallstone ileus usually develops after a past acute cholecystitis. During inflammation from acute cholecystitis and adhesions to adjacent organs, gallstone erodes bladder walls and passes to intestinal lumen through cholecystoenteric fistula. Fistulization usually develops at duodenum; however, it may involve any segment of the stomach, colon or small intestines. If the gallstone is larger than $2-2.5 \mathrm{~cm}$, it may cause obstruction and this obstruction is usually observed in the terminal ileum or ileocecal valve, which is the narrowest area of the intestinal system [5]. Patients generally present with signs and symptoms of intestinal obstruction. It is usually observed in females, between ages of 6575 [5]. However, diagnosis can be difficult due to variable symptoms and this may cause a delay in treatment, being another factor leading to high mortality rate for a benign pathology [8]. Radiopacity and pneumobilia from the ectopic stone is visible in direct abdominal radiography [5]. "Rigler's Triad", a characteristic radiological finding of gallstone ileus, is detected in direct abdominal radiography as small intestine obstruction, pneumobilia and migrating mineral shadow [7]. In our case, there were air-liquid levels of small intestine obstruction, but no pneumobilia and migrating mineral shadow. In a previous ultrasonography of a study, it was stated that $62 \%$ of the cases were diagnosed with cholelithiasis. In the same series of eight cases, only one case $(12.5 \%)$ could be diagnosed with pneumobilia that was detected preoperatively [9]. Computerized tomography (CT) can also be used for detection of pneumobilia and ectopic stone $[2,5,6$, 8]. No CTs were performed for the presented case. Surgery is the treatment for gallstone ileus when it is diagnosed. In some cases with "Bouveret Syndrome", a non-operative treatment option with laser lithotripsy and endoscopic stone extraction method is also 
available [2]. However, the "Bouveret Syndrome" constitutes 1-3\% of gallstone ileus cases and the stone is mostly found in more distal areas that can not be reached by an endoscope [4]. In such cases, surgery is the treatment method. Type of the surgical intervention is also a controversial issue. Enterolithotomy, cholecystectomy and cholecystoduodenal fistula repair can be performed in a single session [1,3]. While this intervention prevents subsequent cholangitis, cholecystitis and ileus secondary to residual gallstones; it also places the patient at increased risk of enteric or biliary fistula. As such surgical interventions also prolong the operation time; they should be performed only in cases with low risk and without cholecystitis and intense inflammatory changes [1]. In an elderly case without accompanying associated diseases or stability, or in the presence of an intense inflammatory process or complex fistula in the surgery, it would be more reasonable to excise the stone, the cause of obstruction, with a simple enterotomy and not to plan any intervention for the gall bladder and fistula $[1,7,9]$. Enterotomy should be performed by advancing the stone to proximal section where no intestinal inflammation is observed. However, in a case accompanied with intense inflammation impacting the stone or malnutrition on the intestinal wall, segmental small intestine resection should be performed to eliminate obstruction [1].

In conclusion, gallstone ileus should be considered for cases in older patients (mostly female) who had no previous surgery or any other detectable cause of mechanical obstruction, but previous or current documented gallstone history. Such cases should be examined using diagnostic methods like direct abdominal radiography, abdominal ultrasonography and, if necessary, CT; and surgery should be performed in line with the above mentioned principles after controlling ileus-related liquid electrolyte disorders and associated medical conditions.

\section{References}

1. Kirchmayr W, Mühlmann G, Zitt M, Bodner J, Weiss H, Klaus A. Gallstone ileus: rare and still controversial. ANZ J Surg 2005; 75: 234-8.

2. Goldstein EB, Savel RH, Pachter HL, Cohen J, Shamamian P. Successful treatment of Bouveret syndrome using holmium: YAG laser lithotripsy. Am Surg 2005; 71: 882-5.

3. Pavlidis TE, Atmatzidis KS, Papaziogas BT, Papaziogas TB. Management of gallstone ileus. J Hepatobiliary Pancreat Surg 2003; 10: 299-302.

4. Sakarya A, Erhan MY, Aydede H, Kara E, Özkol M, İlkgül O, Özsoy Y. Gallstone ileus presenting as gastric outlet obstruction (Bouveret's syndrome): a case report. Acta Chir Belg 2006; 106: 438-40.

5. Abou-Saif A, Al-Kawas FH. Complications of Gallstone disease: Mirizzi syndrome, cholecystocholedochal fistula, and gallstone ileus. The American Journal of Gastroenterology 2002; 2: 249-54.

6. Masannat YA, Caplin S, Brown T. A rare complication of a common disease: Bouveret syndrome, a case report. World J Gastroenterol 2006; 12: 2620-1.

7. Doko M, Zovak M, Kopljar M, Glavan E, Ljubicic N, Hochstädter H. Comparison of surgical treatments of gallstone ileus: preliminary report. World J Surg 2003; 27; 400-4.

8. Barbary C, Orlandini F, Tissier S, Laurent V, Régent D. The gallstone ileus: key points and traps of diagnosis with sliced pictures. J Radiol 2004; 85: 83-90.

9. Gürleyik G, Gürleyik E. Gallstone ileus: demographic and clinical criteria supporting preoperative diagnosis. Ulus Travma Derg 2001; 7: 32-4. 